\title{
Lesestoff von Fortgeschrittenen
}

\section{Erhard Taverna}

Dr. med., Mitglied der Redaktion

Fünf Ärzte melden sich zu Wort. Alle können eine beachtliche Liste von Werken vorzeigen. Enrico Danieli, der vor Jahren den Praktiker mit dem Schriftsteller eingetauscht hat, besticht durch die sezierende Präzision seiner Sprache. Jan A. Fischer setzt seine Sehschule mit Begegnungen und einer privaten Kunstsammlung fort, und Hans Jörg Leu profiliert sich als gewohnt talentierter Schreiber von Kurzgeschichten. Yves E. Patak beweist erneut seinen sechsten Sinn für Übersinnliches mit Gänsehaut, und Andreas Steiner überrascht mit einer Liebesgeschichte und einer Lyrik-Biographie. Allen gemeinsam ist eine ausserordentliche Beobachtungsgabe, die sie in ihre eigene, unverwechselbare Sprache übersetzen.

Andreas Steiner

Der grosse Staatsvertrag um Nathalie

Aachen: Karin Fischer Verlag; 2014.

172 Seiten. 20.4O CHF.

ISBN 978-3-8422-4276-O

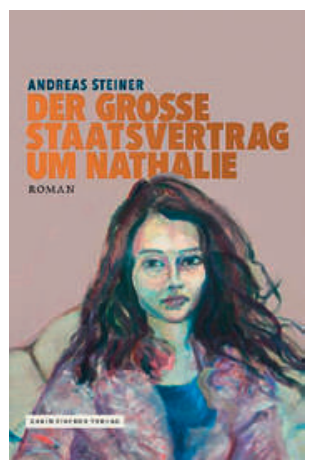

In Andreas Steiners Roman geht es ums Geld, genauer um einen Staatsvertrag mit geheimer Zusatzklausel, genauer um die junge Pianistin Nathalie Pedersen, die gegen lukrative Ölgeschäfte, ohne ihr Wissen, als vierte Ehefrau an einen Emir verschachert wird. Da wird entführt, verfolgt und abgerechnet, Schurken und Helden haben ihren Auftritt, Stützen der Gesellschaft sind ziemlich morsch, und ein frischgebackener Mediziner braucht mehr Grips und Ausdauer als beim Staatsexamen. Die Verfolgungsjagd dauert fast bis zu den finalen Nocturnes und Préludes von Chopin und böte besten Filmstoff für ein abendfüllendes Abenteuer.

Vom gleichen Autor stammt der Lyrikband vis-à-vis.

\section{Enrico Danieli}

Präparieren. Präparat. Präparation.

München: Literareon im Herbert Utz Verlag; 2014.

256 Seiten. 24.40 CHF.

ISBN 978-3-8316-1749-4

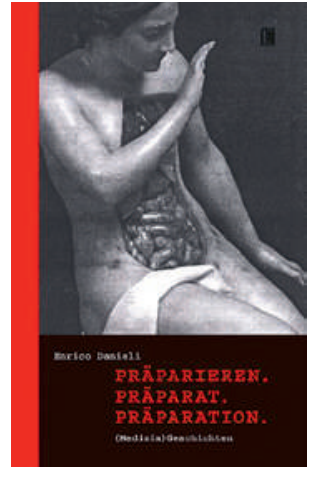

Enrico Danieli präsentiert 78 kurze Texte, die er (Medizin-)Geschichten nennt. Luzide Erinnerungen aus Semester-, Praxis- und Kinderjahren, freie Assoziationen zu Taten und Untaten aus der unmittelbaren Umgebung und der Vergangenheit. Anstelle eines Vorwortes beruft sich der Autor auf die fiktiven und realen Kön-

ner der Mikrotome, Dauerpräparate und Anatomie. Er übernimmt konsequent ihre Fragestellungen, die mehr oder weniger erfolgreich vom Toten auf das Lebendige schliessen. Entstanden sind sorgfältig zugerichtete Präparate, die, mikroskopisch vergrössert, überraschende Einsichten und Querverbindungen offenlegen. Eine Sicht der Dinge, der er im alten botanischen Garten in der Erzählung «Eingelagerte Welten» als reduziertes Modell zur Verbindung ferner Welten wiederbegegnet.

\section{Jan A. Fischer}

Über das Sehen.

Weltumspannende Begegnungen mit Menschen der Kunst

\section{Zürich: Elster Verlag; 2014.}

120 Seiten. 37.90 CHF.

ISBN 978-3-906065-19-9

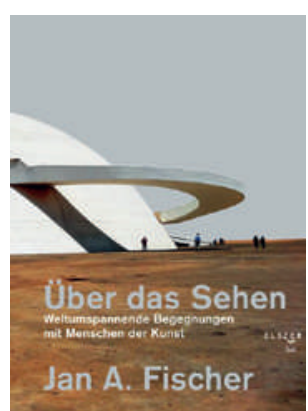

Jan A. Fischer ist ein Weltenbummler der Ästhetik. Für seinen unermüdlichen Wissensdrang ist ihm keine Reise zu beschwerlich. Dieses Mal sind es faszinierende Begegnungen mit Künstlern aus Südamerika, Asien und Russland, bis hin zu globalen Nomaden wie Richard Long, Jaume Plensa, Not Vital und Lichtkünstlern wie Julio Le Parc, James Turrell, Olafur Eliasson und Anthony McCall. Kennern und Laien eröffnet sich eine faszinierende Werkschau moderner Kunst, die kenntnisreich und unterhaltsam in vor- 
bildlicher Art vorgestellt wird. Das sehr schön gestaltete Buch verbindet Augenschmaus mit Lesevergnügen und Entdeckungsreisen mit Lerneffekten. Das Erfassen von Kunstwerken, so der Autor, sei eine Leidenschaft, die zu glücklichen Menschen hinführt. Man darf sich Jan A. Fischer als einen Menschen vorstellen, der sein Glück gerne mit anderen teilt.

Hans Jörg Leu

Glut und Lohe

Egg: Thesis Verlag; 2014.

145 Seiten. 25 CHF.

ISBN 978-3-9085-4428-9

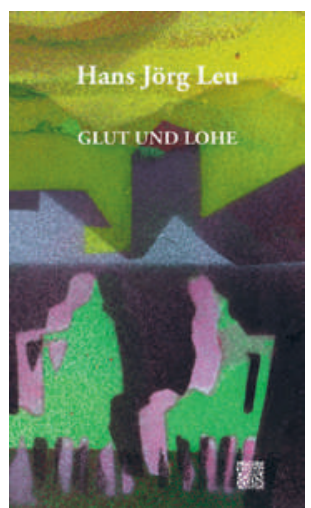

Ohne Geschichten hätte die Welt keine Geschichte, so der Verfasser. Hans Jörg Leu schreibt vom Salz der frühen Jahre, von Schotterwegen der Liebe, vom Blinden, der die Fäden zieht, von Stromausfällen und den Wurzeln an der Reuss. Jeder dieser Titel geht einer Reihe von Erzählungen voran, ein Leitmotiv durch Zeiten und Räume, worin es immer um Begegnungen von Menschen geht. Humorvoll, melancholisch, traurig, belastend, und doch immer gelassen, liebevoll und voller Respekt für die Protagonisten, denen das Schicksal oft mehr zumutet, als sie ertragen können. Leu schreibt seine Lebensbilanzen in einer poetischpräzisen, konzentrierten Sprache. Da steht nichts Überflüssiges, kein Ballast verstellt den Blick auf das Wesentliche. Leu ist auch ein Könner der Verknappung, der Auslassung, die erst recht zum Schwingen bringt, was auch zwischen den Zeilen steht. Eine Hohe Schule des Erzählens, die exemplarisch vorführt, wie man den Leser zu seinen eigenen Bildern hinführt.

Yves E. Patak

\section{Tödlicher Schatten}

Hamburg: Tredition Verlag; 2014.

400 Seiten. 31.40 CHF.

ISBN 978-3-7323-0637-4

Eine Karte von Manhattan orientiert den Reisenden im neusten Thriller von Yves Patak. Ein Mann ver-

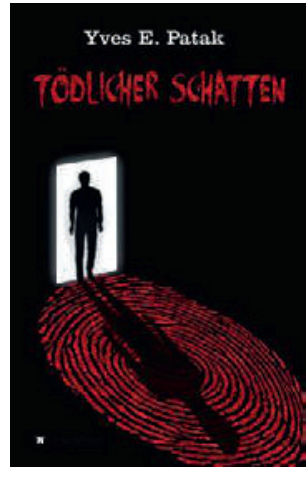

kauft aus Geldnot sein erstes Romanmanuskript an einen Unbekannten. Eine wenig vertrauenerweckende Gestalt, mit einer Passion, Hauptfiguren im Ruhestand zu einem neuen Leben, einer neuen Mission zu verhelfen. Ähnlich wie bei Schlemihl, der in Chamissos Erzählung seinen Schatten verkauft, nimmt eine Geschichte ihren unheilvollen Verlauf, worin Leser und Leserinnen einiges über Autorennöte, Hitzetage in New York, ein zweites KillerIch und die jüdische Kabbala erfahren. Worin auch klar wird, dass Privatdetektive und Psychiater keine Klienten annehmen sollten, denen ein rachsüchtiger Dämon auf den Fersen ist. Ein page turner, wie der Amerikaner sagt, ein Buch, das man gerne ohne Absetzen zu Ende liest. "Baruk atah Adonai, Eloheinu, melekh ha'olam», mehr sei zum Finale nicht verraten.

\section{Andreas Steiner}

\section{Allerlei Verse aus einem halben Jahrhundert}

Aachen: deutscher lyrik verlag; 2014. 144 Seiten. 21.90 CHF.

ISBN 978-3-8422-4329-3

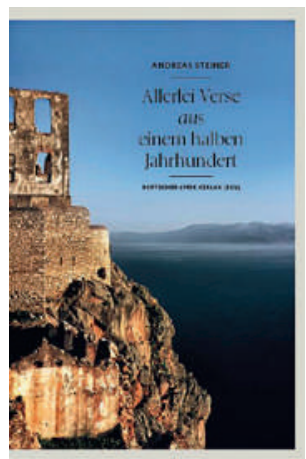

Mit Gedichten über Liebe und Trennung beginnt Andreas Steiner seine Anthologie, die man auch als Biographie in Versform bezeichnen könnte. Sie umfasst die Jahre von der ersten Liebe zu denen ausgedehnter Reisen, führt zu Lebenseinsichten und existenziellen Fragen, zu Aphorismen und Tagebüchern und endet mit dem 70. Geburtstag. Wie bei jeder Lyrik, gibt der Autor mit seiner Sammlung auch vieles von sich selber preis. Es sind echte Perlen darunter, die man nicht so leicht vergisst. Das letzte Gedicht ist mit Aussichtslos überschrieben und endet mit den Strophen: «Lache über dich, du alter Knacker, spotte, bis dein Vorwärtsdrang vergeht! Stopp das literarische Gegacker! Lust auf Ruhm? - Die Zeit hat schon gedreht!» Lieber Andreas Steiner, zum Glück wissen wir es besser. 